\title{
Psychosocial factors as predictors of quality of life and the moderating role of resilience among cancer patients in Lautech Teaching Hospital, Osun State.
}

\author{
Odediji Jumoke Victoria (MNADP) \\ Department of Psychology \\ University of Ibadan \\ Ibadan, Nigeria \\ adejummy24@gmail.com \\ Professor Grace Adejuwon \\ Department of Psychology \\ University of Ibadan \\ Ibadan, Nigeria \\ gaadejuwon@gmail.com \\ DOI: 10.31364/SCIRJ/v9.i04.2021.P0421853 \\ http://dx.doi.org/10.31364/SCIRJ/v9.i04.2021.P0421853
}

\begin{abstract}
Quality of Life (QOL) is an important outcome criterion in oncology and is a major concern of patients with cancer. However, most of them have been conducted in Western countries, and there are relatively few studies of this nature in Nigeria. It is in this light that this study examines the role of coping strategies, dispositional optimism, perceived social support and resilience on quality of life among cancer patients in Osogbo, Osun State. The Buffer theory of social support, stress and coping social support theory serve as the framework for the study. The study adopted a cross-sectional survey research design. A purposive sampling technique was used to select participants for the study.

Data was collected using a structured questionnaire comprising socio-demographic characteristics, coping strategies, dispositional optimism, perceived social support, resilience and quality of life scales. Data was analyzed using zero-order correlation and hierarchical multiple regression analysis.

The study found that coping strategies, dispositional optimism, and perceived social support predicts quality of life. The study also found that resilience moderated the relationship between coping strategies, dispositional optimism, perceived social support, and quality of life. The study concludes that coping strategies, dispositional optimism, and perceived social support are significant predictors of quality of life among cancer patients in Lautech Teaching Hospital, Osogbo, Osun State. Specifically, resilience was a significant moderator of quality of life among cancer patients as it acts as a buffer for cancer patients who have low social supports. The study suggests that quality of life can be improved by helping cancer patients to develop more supportive social networks, high level of optimism, stress coping strategy and building resilience may help in developing wellbeing in form of quality of life.
\end{abstract}

Key Words: Quality of life, Coping Strategies, Resilience, Dispositional Optimism, Perceived Social Support, Moderating Role.

\section{INTRODUCTION}

World Health Organization [36] defined quality of life as individual's perceptions of their position in life in context of the culture and value systems in which they live and in relation to their goals, expectations, standards and concerns. [12] also explains that quality of

www.sciri.org

(C) 2021, Scientific Research Journal

http://dx.doi.org/10.31364/SCIRJ/v9.i04.2021.P0421853

This publication is licensed under Creative Commons Attribution CC BY. 
life is a product of subjective judgment which arises from the overall perception which the individual holds towards what is seen as the significant elements at a particular point in time. Thus, in assessing quality of life, social indicator such as health, subjective well-being measures, cultural and economic indices are very important. The evaluation of ones quality of life is based on the individuals' perception of their health status, which is also influenced by their cultural context and their subjective experiences. [1], in their work affirm that the main components of quality of life are values. These values play a vital role on people's experience; this is because they represent the need and goals that are beneficial to individuals and is essential that individuals fulfill it. Quality of life (QOL) of individuals may be affected in most disease conditions, particularly chronic, lifelong diseases such as cancer. The lifelong nature of the illness and the attendant long treatment regimen contributes significantly to the deterioration of quality of life of people with this illness [2].

Cancer is a major life threatening and the major public health problem of great concern. It is estimated that 1.7 million new cancer cases were diagnosed worldwide in 2012. This makes it the second most common form of cancer following lung cancer [38]. According to world health organization [37], annually around 60,000 new breast cancer cases are diagnosed in Ethiopia. In Nigeria, prevalence rates for cancer are estimated at $10.7 \%$ and $8.7 \%$ in the northern and southern region of the country respectively, which indicate the public health relevance of this illness in the country [17]. In Nigeria, it is worrisome that there are no meaningful programs targeted at this population despite the rate at which people die of this illness [21].

Many studies conducted in Nigeria on quality of life and its associated factors focused on knowledge, attitude and practice, meaning in life, life satisfaction and social support, self-efficacy, positive thinking and optimism, social support, types of diabetes and locus of control, gender and state of residence [8][3][16]. Nevertheless, little is known about the role of social support and psychological capital on quality of life. Hence a gap exists in literature which this present study hopes to fill. Furthermore, most of the past studies [27][8][16] that have researched on quality of life in Nigeria focused on adolescent, health workers, older persons, diabetic patients with few studies, if any on quality of life among hypertensive patients in an emerging country like Nigeria. Lastly, no study to the best of the researcher knowledge in the literature has shown a clear cut mechanism that can explain resilience in the indirect relationship among coping strategies (problem-focused coping and emotion-focused coping), perceived social support and dispositional optimism and quality of life especially among cancer patient in Nigeria. This study will fill all identified lacuna in this area.

Coping strategies can be divided into several categories. [30] defined two essential functions of coping strategies; emotion-focused and problem-focused. [6] distinguished between active and avoidant coping strategies. Active coping represents protective strategies based on an active pursuit to mitigate or eliminate the stress and is related to lower anxiety, stress, and depressive symptoms. Active coping is more efficient in the adjustment to chronic stress than the avoidant one. During the avoidant coping, an individual does not reach out to sort the source of the stress and instead tries to lower own negative emotional reactions. Because the origin of the stress has not been eliminated, the negative emotions keep turning up. Passive avoidance predicts depressive symptoms.

Social support can be defined as the assistance or comfort to other people to help them cope with a variety of problems. Social support comes from interpersonal relationships, family members, neighbors, religious groups and friends. The source of social support can come in the form of emotional support from family, friends, and peers [7]. The availability of social support from family, friends and professionals may boost the recovery of a person who has previously undergone certain challenges of some kind [33]. It can therefore be said that when cancer patients receive no support either from friends, family and significant others, they tend to experience lesser quality of life.

www.scirj.org

(C) 2021, Scientific Research Journal

http://dx.doi.org/10.31364/SCIRJ/v9.i04.2021.P0421853

This publication is licensed under Creative Commons Attribution CC BY. 
Another variable that is important in this study is Dispositional optimism. Optimism refers to the belief that one's outcome from psychological and sociological situations will be positive rather than negative. This refers to the self-serving belief that favorable situations are likely to occur in the face of any circumstance. Optimists are more likely than pessimists to believe that good outcomes are attainable and bad outcomes are avoidable. It can be said that a person with cancer who do not have the belief that they can have a positive outcome from their illness tends to have poor quality of life. Resilience was also introduced to the study as a moderating variable. [28] described resilience as the self-righting tendencies of people. Resilience entails behaviors, thoughts, and actions that individual can learn and can develop in any body. Resilient people cope well, recover better, and benefit from stressful challenges [9]. People that are low in resilience become overwhelmed, that they tend to dwell on problems and employ unhealthy coping mechanism, which can lead to setbacks for individuals facing burnout, as some people perceive challenges greater than others. It can therefore be said that resilience can moderate the relationship between coping strategies (problem-focused coping and emotion-focused coping), perceived social support, dispositional optimism and quality of life.

\section{Review of Related Studies}

I. Coping strategies and quality of life

[29] examined coping strategies and quality of life. The result found that coping strategies influence quality of life among respondents. [25] determined the relationship between stress coping styles and quality of life among patients with breast cancer. The results showed a significant positive relationship between problem-focused coping strategies and two dimensions of QOL including total symptoms and functional scale $(\mathrm{P}=0.01)$. In addition, emotion-focused coping strategies had a significant negative correlation with total symptoms and functional dimension of QOL. [5] investigated the relationship between coping dimensions and overall quality of life. Results showed that patients who used combined emotive coping strategies reported more disability, poorer mental health and worse overall quality of life. [35] examined how coping strategies and perceived social stigmatization predicts the psychological wellbeing of female partners of prisoners in Ibadan, Nigeria. The findings indicates that coping strategies (problem-focused and emotion-focused) and perceived social stigmatization jointly predicted psychological well-being. [23] examined work coping skills and psychological wellbeing in selected fast food companies in Port Harcourt, Nigeria. The findings showed that work coping skills have influence on psychological wellbeing of employees working in fast food companies.

II. Social Support and quality of life

[14] investigated the predictive role of social support and personality traits on psychological wellbeing of postpartum nursing mothers in Oyo State, Nigeria. The results showed that social support and personality traits jointly predicted the four subscales of psychological wellbeing. [35] examined the influence of social support, religion and education on psychological wellbeing among female partners of prisoners in Ibadan, Nigeria. The result revealed that there was significant difference between the psychological wellbeing of partners with low social support and High social support. [19] assessed the relationship between social support and quality of life among psychiatric patients. The study revealed that more than half of the psychiatric patients reported low quality of life and two third of them reported low social support. In addition, there was a statistical significant positive correlation between social support and quality of life. [10] examined whether perceived social support is a meaningful predictor of subjective well-being. 87 students who registered for primary classroom teacher training department joined this survey. It was found that perceived social support predicted $43 \%$ of subjective well-being. [18] examined the social support and the psychological wellbeing of people living with Human Immunodeficiency Virus/Acquired Immunodeficiency syndrome (HIV/AIDS) in Ghana. The result revealed that social support had significant negative association with psychological wellbeing.

III. Optimism and quality of life

www.scirj.org

(C) 2021, Scientific Research Journal

http://dx.doi.org/10.31364/SCIRJ/v9.i04.2021.P0421853

This publication is licensed under Creative Commons Attribution CC BY. 
[13] found out that there was no difference between patients with high optimism and low optimism. One shortfall of the study is that the study did not examine any of the dimensions of optimism as well as quality of life before concluding that there was no role of optimism on quality of life. In another related study done by [4], they explored the role of psychological capital (hope, resilience, optimism and self-efficacy) on the quality of life of caregivers of persons in Lagos state university teaching hospital, Nigeria. Adopting a survey design, data was collected from patients in Lagos state university teaching hospital using a convenient sampling technique. The results of their study showed that psychological capital of hope and optimism significantly predicted quality of life. Also, independently, resilience and self-efficacy did not statistically influence quality of life. The study sample size was small and this could have affected the result findings.

[33] examined the effect of dispositional optimism on the psychological wellbeing of a sample of police officers. The results showed that dispositional optimism have a significant link with psychological wellbeing of respondents. The influence of employees' optimism on subjective wellbeing among corps member in the Southeast, Nigeria was examined by [26]. They discovered in their study that employees' optimism significantly and positively predicted subjective wellbeing among the sampled respondents. The study did not look at resilience on the objective wellbeing of the respondents of the study.

\section{Resilience and quality of life}

[13] examined the impact of resilience on environmental quality of life from the Badagry oil-producing community. They found out in their study that there was influence of resilience on environmental QOL among the sampled respondents. Despite the relevance of their study, the study failed to look at the dimensions of resilience on sub-domains of quality of life. [19] examined the role of resilience and well-being of university nursing students. It was revealed in their study that self-reported resilience had a positive link with perceived well-being. [7] examined the relationship between resilience and mental health. The result revealed that resilience has a negative link with depression while there was a positively link with mental well-being.

Hypotheses

1. Coping strategies (problem-focused coping and emotion-focused coping) will significantly jointly and independently predict quality of life among cancer patients in Lautech Teaching Hospital, Osogbo, Osun State

2. Coping strategies (problem-focused coping and emotion-focused coping), Resilience, Social Support and Dispositional Optimism will significantly jointly and independently predict quality of life among cancer patients in Lautech Teaching Hospital, Osogbo, Osun State.

3. Resilience will significantly moderate the influence of coping strategies, perceived social support, and dispositional optimism on quality of life among cancer patients in Lautech Teaching Hospital, Osogbo, Osun State.

Methods

\section{Study Design}

A cross-sectional survey research design was adopted with the use of questionnaire to generate responses from the research participants. Questionnaire was used to gather data from cancer patients in Lautech Teaching Hospital, which is an important provider of cancer treatment in Osogbo, Osun State. The survey instrument consisted of six questionnaires: a socio-demographic characteristics, the Filipino Coping Strategies Scale (FCSS), the Life Orientation Test (LOT) revised, the Multidimensional Scale of Perceived Social 
Support (MSPSS), the Connor-Davidson Resilience Scale and the Quality of Life Scale. Initially, a total of 150 cancer patients were given questionnaires. Finally, one hundred and eight (108) effective responses were received from cancer patients.

\section{Setting}

The research study was conducted in Lautech Teaching hospital in Osogbo, Osun State, Nigeria. Lautech Teaching Hospital, Osogbo was founded in 1928 by the British Colonial Administration as a 15-bed capacity "African Hospital" primarily to cater for the medical needs of black people in the area, known as Osun and Ife/Ijesha medical areas. The Teaching Hospital was jointly established by Oyo State and Osun State.

\section{Sample Size Determination}

Sampling size was determined using sample size calculation method developed by Yamane (1967) formula $\mathrm{n}=\frac{N}{1+N\left(e^{2}\right)}$ Where; $\mathrm{n}=$ required sample size

$\mathrm{N}=$ is the population size with $\pm 5 \%$ precision.

$$
\mathrm{N}=150, \mathrm{e}=0.05
$$

$\mathrm{n}=\frac{150}{1+150\left(0.05^{2}\right)}=109$ participants

However, only one hundred and eight (108) was used for the study.

IV. Sampling technique

The purposive sampling technique was employed for the study. This is because the researcher already knows the characteristic of the participants. The inclusion criteria of the study includes: Participants must be diagnosed with cancer for about 2 months, Participants must be receiving treatment from the Hospital, and, Participants must indicate willingness to participate in the study.

\section{Participants}

Respondents' mean age was 34.34. For ethnicity, 51.9\% were Yoruba, 31.5\% were Hausa, and 16.7\% were Igbo. For marital status, $24.1 \%$ were single, $70.4 \%$ were married, $4.6 \%$ were widows/widowers and $0.9 \%$ was separated. For religion, $40.7 \%$ were Christians, $59.3 \%$ were Muslims. For Level of education, 53.7\% were SSCE holders, 29.6\% were Ordinary National Diploma (OND) holders, 13.0\% were Bachelor of Science/Higher National Diploma (BSC/HND) holders, and 3.7\% were Master of Science (MSC) holders. For gender, $28.7 \%$ were males, $71.3 \%$ were females. For occupation, $48.1 \%$ were employed, 51.9\% were unemployed. For monthly income, $28.7 \%$ were earning less than \#20,000, 54.6\% were earning between \#20001 - \#40,000, 14.8\% were earning between \#40001 - \#60,000, and $1.9 \%$ were earning \#60001 and above.

\section{Instruments}

I. Measurement of Quality of life

Quality of life was measured with the Quality of life scale. The scale consist of 37 items quality of life scale. The 37-item scale was rated on a 4-point Likert response format ranging from 1-Never to 4-Always. Cronbach alpha reliability for the scale is 0.93 . Score

www.scirj.org

(C) 2021, Scientific Research Journal

http://dx.doi.org/10.31364/SCIRJ/v9.i04.2021.P0421853

This publication is licensed under Creative Commons Attribution CC BY. 
above the mean implies that the individual perceived higher quality of life and vice versa. In this study, the Cronbach alpha reliability score obtained was 0.75 .

\section{Measurement of Coping Strategies}

Coping strategies was measured with the Filipino Coping Strategies Scale (FCSS). The FCSS is a 37-item scale designed by [34] to measure the coping strategies towards stress. The FCSS comprise the cognitive reappraisal domain, social support domain, problemsolving domain, religiosity domain, tolerance domain, emotional release domain, over-activity domain, relaxation/recreation domain and substance use domain. The 37 items were rated on 4-point Likert response format ranging from 1- Never to 4 - Always. Cronbach alpha reliability for the scale is 0.72 . Score above the mean implies a greater degree of hopelessness and vice versa. In this study, the Cronbach alpha reliability score obtained was 0.64 .

III. Measurement of Dispositional Optimism Scale

Dispositional optimism was measured with the Life Orientation Test (LOT) revised. The 10-item scale was rated on a 5-point Likert response format ranging from A- I Agree a lot, to E-I Disagree a lot. In this study, the Cronbach alpha reliability score obtained was 0.93 .

\section{Measurement of Perceived Social Support (MSPSS)}

Perceived Social Support was measured with the Multidimensional Scale of Perceived Social Support (MSPSS) developed by [16] and it consist of 12 items. The 12-item scale was rated on a 7-point Likert response format ranging from 1-Very strongly disagree to 7-very strongly agree. Cronbach alpha reliability for the scale is 0.88 , overall score on the scale range from $12-69$. Score above the mean implies that the individual perceived higher social support and vice versa.

\section{Measurement of Resilience}

Resilience was measured with the Connor-Davidson Resilience Scale 10-item Version developed by [22]. The scale consists of 10 items and is structured as a 5-point Likert-type cumulative instrument ranging from $0=$ Never to $4=$ always. [22] obtained the Cronbach alpha reliability of 0.81 . Score above the mean implies higher level of resilience. In this study, the Cronbach alpha reliability score obtained was 0.88 .

Statistical Analysis

The collected data was analyzed using the Statistical Package for IBM-Social Sciences (SPSS) version 24. Descriptive and inferential statistics was used for the analysis of the data collected from the respondents. The descriptive statistics was used to analyze the demographic variables while the inferential statistics was used to test the hypotheses in the study. Hypothesis one and two were tested using multiple regression analysis. Correlation among psychological variables were examined.

www.scirj.org

(C) 2021, Scientific Research Journal

http://dx.doi.org/10.31364/SCIRJ/v9.i04.2021.P0421853

This publication is licensed under Creative Commons Attribution CC BY. 
Results

Table I: Summary of Zero Order Correlations among Psychological Variables and Quality of Life

\begin{tabular}{|c|c|c|c|c|c|c|c|c|}
\hline Variables & 1 & 2 & 3 & 4 & 5 & 6 & Mean & SD \\
\hline $\begin{array}{l}\text { 1.Coping } \\
\text { Problem-Focused }\end{array}$ & 1 & -0.152 & $0.920^{* *}$ & $0.899^{* *}$ & $0.935^{* *}$ & $0.856^{* *}$ & 64.23 & 13.82 \\
\hline $\begin{array}{l}\text { 2.Emotion- } \\
\text { Focused }\end{array}$ & & 1 & -0.089 & 0.011 & -0.083 & -0.177 & 48.44 & 26.08 \\
\hline 3.Resilience & & & 1 & $0.969^{* *}$ & $0.992^{* *}$ & $0.694^{* *}$ & 30.69 & 8.63 \\
\hline 4.Social Support & & & & 1 & $0.971^{* *}$ & $0.691^{* *}$ & 36.51 & 18.39 \\
\hline 5.Optimism & & & & & 1 & $0.735^{* *}$ & 34.34 & 8.30 \\
\hline 6.Quality of life & & & & & & 1 & 90.69 & 36.20 \\
\hline
\end{tabular}

(* Correlation is significant at the 0.05 level (2-tailed))

As shown in Table I, problem-focused coping had a significant and very strong positive relationship with quality of life among cancer patients $(\mathrm{r}=0.86, \mathrm{p}<0.01)$. This implies that as the patients continue applying problem-focused coping, the better their quality of life and vice-versa. Further, findings revealed that resilience increases quality of life among cancer patients $(\mathrm{r}=0.69$,p $<0.01)$; also, result showed that social support had significant positive relationship with quality of life $(r=0.69, \mathrm{p}<0.01)$, optimism had significant and strong positive relationship with quality of life among cancer patients in Lautech Teaching Hospital, Osogbo, Osun State. However, only emotionalfocused coping had no significant relationship with quality of life among cancer patients in the study at ( $\mathrm{r}=-0.177, \mathrm{p}>0.05)$.

\section{Hypothesis One}

Coping strategies (problem-focused coping and emotion-focused coping) will significantly jointly and independently predict quality of life among cancer patients in Lautech Teaching Hospital, Osogbo, Osun State. This was tested using multiple regression analysis. The results are presented in Table II.

Table II: Multiple Regressions Showing Coping strategies as predictors of Quality of Life among Cancer Patients in Lautech Teaching Hospital, Osogbo, Osun State.

\begin{tabular}{llllllll} 
Predictors & $\mathrm{B}$ & $\mathrm{T}$ & $\mathrm{P}$ & $R$ & $R^{2}$ & $F(2,105)$ & $P$ \\
\hline Problem-focused coping & 0.849 & 16.712 & $<0.01$ & & & & \\
Emotion-focused coping & -0.047 & -0.927 & $>0.05$ & 0.857 & 0.735 & 145.83 & $<0.01$ \\
\hline
\end{tabular}

(Dependent Variable (DV): Quality of Life)

The results in Table II revealed that coping strategies (problem-focused coping and emotion-focused coping) significantly jointly predicted quality of life among cancer patients in Lautech Teaching Hospital, Osogbo, Osun $\mathrm{State},\left(\mathrm{R}=0.857, \mathrm{R}^{2}=0.74, \mathrm{~F}(2,105)=\right.$ 145.83, $\mathrm{p}<0.01$ ); this implies that problem-focused coping and emotion-focused coping accounted for $74 \%$ of the changes observed in the self-report level of quality of life among cancer patients while the remaining $26 \%$ could be attributed to alienated factors not by chance considered in the study. Further findings showed the significant independent contributions of problem-focused coping to the variance in the quality of life; $85 \%$ variance in quality of life $(\beta=0.849, \mathrm{t}=16.712 ; \mathrm{p}<0.01)$; emotion-focused coping had no significant independent effect on quality of life $(\beta=0.047, \mathrm{t}=-0.927 ; \mathrm{p}>0.05)$. The overall results largely supported the stated hypothesis and it is accepted.

II. Hypothesis two

www.scirj.org

(C) 2021, Scientific Research Journal

http://dx.doi.org/10.31364/SCIRJ/v9.i04.2021.P0421853

This publication is licensed under Creative Commons Attribution CC BY. 
Resilience, social support and dispositional optimism will significantly jointly and independently predict quality of life among cancer patients in Lautech Teaching Hospital, Osogbo, Osun State. This was tested using multiple regression analysis. The results are presented in Table III.

Table III: Multiple Regressions Showing resilience, social support and optimism as predictors of Quality of Life among Cancer Patients in Lautech Teaching Hospital, Osogbo, Osun State.

\begin{tabular}{lccccccc} 
Predictors & $\mathrm{B}$ & $\mathrm{T}$ & $\mathrm{P}$ & $R$ & $R^{2}$ & $F(3,104)$ & $P$ \\
\hline Resilience & 0.215 & 4.170 & $<0.01$ & & & & \\
Social Support & -0.160 & -0.614 & $>0.05$ & 0.783 & 0.614 & 55.07 & $<0.01$ \\
Optimism & 0.188 & 5.824 & $<0.01$ & & & & \\
\hline
\end{tabular}

(DV: Quality of Life)

The results in Table III revealed that resilience, social support and dispositional optimism significantly jointly predicted quality of life among cancer patients in Lautech Teaching Hospital, Osogbo, Osun State, $\left(\mathrm{R}=0.783, \mathrm{R}^{2}=0.614, \mathrm{~F}(3,104)=55.07, \mathrm{p}<0.01\right)$; this implies that resilience, social support and dispositional optimism accounted for $61.4 \%$ variance in quality of life among cancer patients while the remaining $38.6 \%$ could be attributed to alienated factors not by chance considered in the study. Further findings showed the significant independent contributions of resilience to the variance in the quality of life $(\beta=0.215, \mathrm{t}=4.170 ; \mathrm{p}<0.01)$; dispositional optimism had significant independent effect on quality of life $(\beta=0.188, \mathrm{t}=2.015 ; \mathrm{p}<0.01)$. The overall results largely supported the stated hypothesis and it is accepted.

III. Hypothesis Three

Resilience will significantly moderate the influence of coping strategies, social support, and dispositional optimism on quality of life among cancer patients in Lautech Teaching Hospital, Osogbo, Osun State. This hypothesis was tested using hierarchical multiple regressions and the results are presented in Table IV.

Table IV: Summary of Hierarchical Regression Showing the Moderating Effect of Resilience on coping strategies, social support, and dispositional optimism as predictors of quality of life among cancer patients in Lautech Teaching Hospital, Osogbo, Osun State.

\begin{tabular}{|c|c|c|c|c|c|c|c|c|}
\hline \multicolumn{2}{|c|}{ Predictors } & \multirow[t]{2}{*}{ Beta } & \multirow[t]{2}{*}{$\mathrm{T}$} & \multicolumn{5}{|l|}{ Sig } \\
\hline & & & & & $\mathrm{R}$ & $\mathrm{R}^{2}$ & $\mathrm{~F}$ & Sig \\
\hline \multirow{6}{*}{1} & (Constant) & & 3.229 & 0.002 & \multirow{6}{*}{$0.322^{\mathrm{a}}$} & \multirow{6}{*}{0.104} & \multirow{6}{*}{2.362} & \multirow{6}{*}{$<0.05$} \\
\hline & Resilience & 0.205 & 2.122 & 0.036 & & & & \\
\hline & Coping Problem-Focused & 0.138 & 1.303 & 0.195 & & & & \\
\hline & Emotion-Focused & -0.251 & -1.555 & 0.123 & & & & \\
\hline & Social Support & 0.116 & 0.666 & 0.507 & & & & \\
\hline & Optimism & 0.127 & 1.316 & 0.191 & & & & \\
\hline \multirow{5}{*}{2} & (Constant) & & 3.576 & 0.001 & \multirow{5}{*}{$0.316^{\mathrm{b}}$} & \multirow{5}{*}{0.100} & \multirow{5}{*}{2.858} & \multirow{5}{*}{$<0.05$} \\
\hline & Social support & 0.195 & 2.053 & 0.043 & & & & \\
\hline & Coping Problem-focused & 0.108 & 1.131 & 0.261 & & & & \\
\hline & Emotion-focused & -0.164 & -1.730 & 0.087 & & & & \\
\hline & Optimism & 0.136 & 1.427 & 0.157 & & & & \\
\hline \multirow{4}{*}{3} & (Constant) & & 5.831 & 0.000 & \multirow[b]{4}{*}{$0.298^{c}$} & \multirow[b]{4}{*}{0.089} & \multirow[b]{4}{*}{3.375} & \multirow[b]{4}{*}{$<0.05$} \\
\hline & Coping Problem-Focused & 0.209 & 2.205 & 0.030 & & & & \\
\hline & Emotion-Focused & -0.180 & -1.914 & 0.058 & & & & \\
\hline & Optimism & 0.152 & 1.602 & 0.112 & & & & \\
\hline \multirow{3}{*}{4} & (Constant) & & 9.069 & 0.000 & \multirow[b]{3}{*}{$0.257^{\mathrm{d}}$} & \multirow[b]{3}{*}{0.066} & & \multirow[b]{3}{*}{$<0.05$} \\
\hline & Coping Problem-focused & 0.187 & 1.985 & 0.050 & & & & \\
\hline & Emotion-Focused & -0.169 & -1.796 & 0.075 & & & 3.724 & \\
\hline
\end{tabular}

(Moderating Variable: Resilience)

$D V=$ Quality of Life) 
As shown in Table IV, the results of the hierarchical multiple regressions revealed that in the first model, when all the independent variables were introduced with the moderating factor (resilience), i.e. the joint contributions of the model was $10.4 \%$ variance ( $\mathrm{R}=0.322$, $\mathrm{R}^{2}=0.104, \mathrm{~F}=2.362, \mathrm{P}<0.001$ ) in quality of life among cancer patients Lautech Teaching Hospital, Osogbo, Osun State. In the second model, when the moderating factor (resilience) was removed, the model yielded a lesser variance of about $10 \%$ in quality of life $\left(\mathrm{R}=0.316, \mathrm{R}^{2}=0.100, \mathrm{~F}=2.858, \mathrm{P}<0.05\right)$.

In the third model, when coping problem-focused, dispositional optimism and emotional-focused coping were retained, the model yielded a lesser variance of about $8.9 \%$ in quality of life among cancer patients $\left(R=0.298, R^{2}=0.089, F=3.375, P<0.05\right)$. Finally in the fourth model when only coping strategies were examined as predicting quality of life, result shows that the model accounted for $6.6 \%$ variance in quality of life $\left(\mathrm{R}=0.257, \mathrm{R}^{2}=0.066, \mathrm{~F}=3.724, \mathrm{P}<0.05\right)$. Therefore, the results confirmed the moderating role of resilience on coping strategies, social support and dispositional optimism and the stated hypothesis is accepted.

\section{Discussion}

The first hypothesis which stated that coping strategies (problem-focused coping and emotion-focused coping) will significantly jointly and independently predict quality of life among cancer patients in Lautech Teaching Hospital was confirmed. The hypothesis revealed that coping strategies (problem-focused coping and emotion-focused coping) significantly jointly predicted quality of life among cancer patients, while only problem-focused coping have independent prediction on quality of life. The study finding was in line with the study done by [31] who found that coping strategies influence quality of life among respondents. The study was also in line with [38] who found that coping strategies (problem-focused and emotion-focused) and perceived social stigmatization jointly predicted psychological well-being.

The second hypothesis found that resilience, social support and dispositional optimism will significantly jointly and independently predict quality of life among cancer patients. The study found that resilience, social support and dispositional optimism predicts quality of life. The study was in line with [38] that found that coping strategies (problem-focused and emotion-focused) and perceived social stigmatization jointly predicted psychological well-being. The study was also in line with [38] that revealed that there was significant difference between the psychological wellbeing of partners with low social support and high social support. The study was not in accordance with [32] that found out that there was no difference between patients with high optimism and low optimism.

The third hypothesis that stated that resilience will significantly moderate the influence of coping strategies, social support, and dispositional optimism on quality of life was also confirmed. The study found that resilience moderated the influence of coping strategies, social support, and dispositional optimism on quality of life. The study findings was in line with [38] that also investigated the influence of resilience on psychological wellbeing among employees. They were able to find in their study that resilience has influence on psychological wellbeing. The study finding was also in line with [24] who found that there was a strong positive association between resilience and quality of life. The study was also in line with [35] where they found that resilience was seen to be a strong indicator of quality of life.

Conclusion

The study concluded that coping strategies (problem-focused coping and emotion-focused coping) significantly determine quality of life among cancer patients in Lautech Teaching Hospital, Osogbo, Osun State. The study concluded that resilience, perceived social support and dispositional optimism influence quality of life among cancer patients in Lautech Teaching Hospital, Osogbo, Osun State. Finally, resilience moderates the role of coping strategies, perceived social support, and dispositional optimism on quality of life among

www.scirj.org

(C) 2021, Scientific Research Journal

http://dx.doi.org/10.31364/SCIRJ/v9.i04.2021.P0421853

This publication is licensed under Creative Commons Attribution CC BY. 
cancer patients. This findings suggest that helping cancer patients to develop more supportive social networks, high level of optimism, stress coping strategy, and building hope may help in developing well-being in form of quality of life.

Recommendations

Based on these findings, the following recommendations were made, cancer prevention programs, counseling centers, psycho-education, and psychology clinics in university teaching hospitals should include personality, as well as social support, and coping strategies, in their assessment and identification of individuals who may be at risk of cancer. Clinicians and practitioners can use coping strategies and personality factors (dispositional optimism) to identify quality of life of cancer patients.

Limitations of the Study

There are some limitations in the study. First, the study was limited to Lautech Teaching Hospital only; if patients from other private hospitals were included in the study, it would have given a larger perspective to the findings and could have yielded more robust findings. Second, all the data were based on self-report, and might be subject to self-reporting bias. Furthermore, questionnaires were the only tool used to gather information from the respondents. A combination of questionnaire with structured interview might have yielded varied and deeper findings in the study.

Acknowlegment

I am most grateful to God Almighty, the sole provider of knowledge, wisdom, and grace for His protections throughout the period of the project. I sincerely appreciate my supervisor, Prof. Grace Adejuwon who offered timely criticism and corrections that led me through the various stages of the project. I also appreciate my parents and siblings for their moral and financial support throughout the project. A special thanks to Folorunso Kazeem Dolapo for his kind gesture towards the project. Also to my friends, Adeyemi Samuel Adeniyi, Ishola Fiyinfolu, Olisa Raymond and the ELITES for their support and encouragement to complete the project.

References

[1] A. Adejumobi, and O. Odunmosu, "Survey of quality of life of Nigerians", Ibadan: Nigeria Institute of Social and Economic Research, 1998.

[2] A.M. Hassen, G. Taye, M. Gizaw, F.M. Hussien, "Quality of life and associated factors among patients with breast cancer under chemotherapy at Tikur Anbessa specialized hospital, Addis Ababa, Ethiopia”. PLoS ONE 14(9): e0222629, 2019.

[3] A.O. Adewuya, and O.O. Adeyeye, "Anxiety and depression among Nigerian patients with asthma", Association with sociodemographic, clinical, and personality factors. J asthma 2017; 54(3):286-293, 2017.

[4] A. Obosi, and E. Izedomi, "Quality of life among caregivers of persons living with sickle cell anemia: the influence of Psycho-social factors", Psychological Behaviour Science International Journal 10(2), 55-65, 2018.

[5] A. Wahl, B. Hanestad, I. Wiklund, and T. Moum, "Coping and quality of life in patients with psoriasis", Quality of Life Research, Volume 8, Issue 5, pp 427-433, 1999.

[6] B.E. Compas et al., "Latent variable analysis of coping, anxiety/depression, and somatic symptoms in adolescents with chronic pain". Journal of Consulting and Clinical Psychology; 74: 1132-1142, 2006.

[7] C. Yong, and J. Lyu, "Resilience and mental health among older koreans: focusing on depression and mental well-being", Innovation in Aging, 2, (1), 994-995, 2018.

[8] E. Greenberger, C.S. Chen, S.R. Tally, and Q. Dong, "Family, peer, and individual correlates of depressive symptomatology among US and Chinese adolescents". Journal of Consulting and Clinical Psychology, 68(2), 209-219, 2000.

[9] E. Ilevbare, E. Idehen, and F. Ilevbare, "Influence of psychosocial factors on the quality of life of diabetics patients at Obafemi Awolowo University Teaching Hospital”, Ife Psychologia, 24(1), 66-75, 2016.

$$
\text { www.sciri.org }
$$

(C) 2021, Scientific Research Journal

http://dx.doi.org/10.31364/SCIRJ/v9.i04.2021.P0421853

This publication is licensed under Creative Commons Attribution CC BY. 
[10] E.W. Farber et al. "Resilience factors associated with adaptation to HIV disease", Psychosomatics, 41 (2000), pp. 140-146.

[11] F. Gülaçti, "The effect of perceived social support on subjective well-being”, Procedia Social and Behavioral Sciences 2, 3844-3849, 2010.

[12] F. Helen et al. "Quality of life of older persons: do gender and state of residence have any role?" Gender \& Zac Behaviour, Vol. 18 No. 2, June 2020.

[13] F.L. Amao, "Quality of life of poor residential neighborhoods in Osogbo, Nigeria", International Scholarly and Scientific Research and Innovation, 8(4), 914-917, 2014.

[14] F.M. Ilevbare, and E.S. Idemudia, "Examining the role of resilience and perceived health status on environmental quality of life: An oil community experience”, Environmental Quality Management, 28, 7-15, 2018.

[15] G. Adejuwon, I. Adekunle, and M. Ojeniran, "Social support and personality traits as predictors of psychological wellbeing of postpartum nursing mothers in Oyo State, Nigeria”, International Journal of Caring Sciences 11(2), 704-718, 2018.

[16] G.D. Zimet, N.W. Dahlem, S.G. Zimet, and G.K. Farley, "The multidimensional scale of perceived social support”. Journal of Personality Assessment, 52, 30-41, 1988.

[17] H. Olagundoye, O. Owoseni, D. Fagbenro, and E. Omole, "Quality of life of older persons: do gender and state of residence have any role?" Gender \& Behaviour, Vol. 18 No. 2, 15728- 15737, 2020.

[18] I.A. Yakassai, E.A. Ugwa, and J. Otubu "Malignancies in Aminu Kano Teaching Hospital Kano: a 3 year review", Nigerian Journal Clinical Practice, 16(1), 63-72, 2013.

[19] K. Asante, "Social support and the psychological wellbeing”. African Journal Psychiatry, 15:340-345, 2012.

[20] K. Chowe, O. Tang, E. Chan, P. Sit, and U. Choi, "Resilience and well-being of university nursing students in Hong Kong: a cross-sectional study", BMC Medical Education BMC series, 18, 13-24, 2018.

[21] K. Mahmoud, Y. Berma, and T. Gabal, "Relationship between social support and the quality of life among psychiatric patients", Journal of Psychiatry and Psychiatric Disorders, 5, 67-78, 2017.

[22] K.M. Connor, J.R. Davidson, "Development of a new resilience scale: The Connor-Davidson resilience scale (CD-RISC)". Depression and anxiety. 2003; 18(2):76-82.

[23] Lebimoyo, B. Ola, B. Adewuya, O. Atilola, and A. Popoola, "Mental health and quality of life among patients with gynaecological cancers in Lagos, Nigeria”, MJP Online Early 12, 24-36, 2020.

[24] L. Sambu, "Resilience and quality of life among the internally displaced persons after trauma: a case of Kiambaa village in Uasin Gishu County, Kenya", British Journal of Psychology Research, 3,(3), 23-34, 2015.

[25] M.K Ibe, and W.O. Olori, "Work coping skill and psychological wellbeing in selected fast food companies in Portharcourt, Nigeria", International Journal of Advanced Academic Research in Social \& Management Sciences, 2 6(8), 8-17, 2016.

[26] M. Scheier, and C. Carver, "Optimism, coping and health: assessment and implication of generalized outcome expectancies", Health Psychology, 4, 219-47, 2005.

[27] N. Maleknia, and F. Kahrazei, "The relationship between stress coping styles and quality of life among patients with breast cancer", Journal of Midwifery and Reproductive Health. 2015; 3(4): 472-478.

[28] O. Fabian, Ugwu \& Dorothy, and I. Aumbur, "Going beyond borders: work centrality, emotional intelligence and employee optimism as predictors of organizational citizenship behavior”, Cogent Psychology, 4:1362805, 2017.

[29] O. Famakinde, and A. Obosi, "The role of self-efficacy, positive thinking and optimism on quality of life among HIV patient in University College Hospital and Adeoyo Maternity Hospital in Ibadan". African journal for the psychological study of social issue, 20(3), 302-315, 2017.

www.scirj.org

(C) 2021, Scientific Research Journal

http://dx.doi.org/10.31364/SCIRJ/v9.i04.2021.P0421853

This publication is licensed under Creative Commons Attribution CC BY. 
[30] O. McManus, T. Werner, and E. Smith, "Psychobiological mechanism of resilience and vulnerability: implications for successful adaptation to extreme stress", American Journal of Psychiatry; 161, 195-216, 2010.

[31] P. Baumstarck, "Coping strategies and quality of life: a longitudinal study of high-grade glioma patient-caregiver dyads", Health and Quality of Life Outcomes. Journal of health, 12, 23-32, 2018.

[32] P. Olapegba, and E. Obosi, "The role of self-efficacy, positive thinking and optimism on quality of life among HIV patient in university college hospital (UCH) and Adeoyo maternity hospital in Ibadan”, African journal for the psychological study of social issues 20(3), 302-315, 2017.

[33] R.S. Lazarus, and S. Folkman, "Stress, appraisal, and coping”. New York: Springer, 1984.

[34] R. John C Rilveria, “The development of the Filipino coping strategies scale”, Research Article; year 2018, vol 18; 111 -126.

[35] Simmons and Yoder; "Military resilience: a concept analysis", February 2013 Nursing Forum 48(1):17-25.

[36] S. Odedokun, "Impact of emotional intelligence, dispositional optimism and emotional exhaustion on the psychological wellbeing of police officers in Ibadan, Oyo State, Nigeria", International Journal of Innovation and Applied Studies, 19 (3), 3-12, 2017.

[37] T. Seeman, "Support and social conflicts", Section one-social support: Research psychosocial notebook, 2008.

[38] Ugwu, O. Fabian, Onyishi, M. Alma, and Rodriguez-Sanches, "Linking organizational trust with employee engagement: the role of psychological empowerment", 2014.

[39] V. Bada, S. Balogun, and G. Adejuwon, "Psychological factors predicting psychological wellbeing among spouses of incarcerated males in Ibadan, Nigeria”, Sci. Know HC, 1(3), 76-82, 2014.

[40] World Health Organization, "Preventing chronic diseases: a vital investment", World Health Organization, Geneva 2005 [cited 2012/01/15].

[41] World Health Organization, "Constitution of the World Health Organization" World Health Organization, Geneva: Switzerland, 2000.

[42] World Health Organization: "Latest world cancer statistics" Geneva: International Agency for Research on Cancer (IARC), 2015.

[43] World Health Organization, "Constitution of the World Health Organization" World Health Organization, Geneva: Switzerland, 2013.

[44] Yamane and Taro, "Statistics, an introductory analysis", 2 ${ }^{\text {nd }}$ Ed., New York: Harper and Row, 1967.

www.scirj.org

(C) 2021, Scientific Research Journal

http://dx.doi.org/10.31364/SCIRJ/v9.i04.2021.P0421853

This publication is licensed under Creative Commons Attribution CC BY. 